\title{
Perceptions of Citizen Affiliated with Community Based Institutions on Social Norms and Practices Related to Adolescent Sexual and Reproductive Health in Baitadi District of Nepal
}

Giri Prasad Panthi

\section{Abstract}

The study attempted to explore and analyze perceptions of citizens affiliated with Community Based Institutions on social norms and practices related to adolescent sexual and reproductive health in Baitadi district of Nepal. The objective of this study was to assess social acceptance level of citizen to challenge prevailing social norms and their readiness to abandon unhealthy traditional practices related to sexual and reproductive health as a social accountability. Descriptive and analytical research design was used to take the citizens perspectives. A total of 337 respondents affiliated with the five different types of Community Based Institutions (CBIs) were interviewed using structured questionnaire for data collection and data analysis was done by using SPSS version 16.0. The findings of the study revealed that majority of citizens were sticky on traditional social norms and practices. Majority of citizens were not agree to allow adolescent girls to go to school during mensuration, to allow (c) (1) (9) This work is licensed under the Creative Commons (C) Giri 


\section{2| Giri Prasad Panthi}

to stay inside home during mensuration and talking about sex and sexuality between parents and adolescents. Therefore, there is a need of social norms change and step up for positive social deviant by citizen leaders to promote enabling social environment for adolescent sexual and reproductive health.

Keywords: Chhaupadhi, Social Norms, Traditional Practices, Norms Change, Positive Social Deviant

\section{Introduction}

There are many traditional unhealthy practices in Nepal which cause immediate and long term debilitating effect on the health and development of adolescents especially girls. The common traditional practice in far and mid-western Nepal is social restrictions during mensuration and delivery.

Mensuration is normal biological phenomena which starts in the adolescent age of female normally between the ages of 1115 years. There are several taboos and beliefs around the world regarding mensuration, mensural blood, menstruating women and such taboos are deeply rooted in the religious, social and cultural ground and expressed in the form of different practices (Crawford et.al, 2014). Based on the concept of impurity, separation of girls and women from their family, social- cultural religious- restrictions and embarrassment to adolescent girls and women during menstruation and delivery period is in practice throughout Nepal. However, degree and type of banishment differs among geographical communities (Kadariya \& Aro, 2015).

According to the report of multi indicators survey more rigid and rampant banishment is find in far western districts of Nepal called 'Chhaupadhi'. In Chhaupadhi practice women during 
Dhaulagiri Journal of Sociology and Anthropology Vol.11, 2017|153 their menstrual period and after delivery have to stay in separate house or animal shed. During that period, nutritious foods are not allowed to eat, that period women are not allowed to participate in public meeting. This kind of living arrangement, isolation and discriminatory practices affect women both physically and mentally. Despite Chhaupadhi tradition was outlawed by the supreme court of Nepal in 2005, it continues to exist due to illiteracy, superstitious beliefs, gender disparity, strong community beliefs and deeprooted traditions especially in the Far and Mid-Western regions of Nepal. Girls from these areas even have to miss school for 4-11 days ever month during their mensural periods every even in their examination which severely limiting their future, educational and lifelong socio-economic opportunities. The Multi Indicators Survey (MIS) conducted in 2010 has revealed that in Mid-western and Far western region about eight percent of the girls were absent from school during their menstruation period (CBS \& UNICE, 2010). This further increases the disparity between boys and girls on secondary and higher levels of education. In this regions, there is a normative expectations from the community that menstruating girls should not enter the schools and temples.

Moreover, adolescent girls have to face many physical and emotional problems during their menstrual period. Studies have shown that Girls from families with poor socioeconomic status are more vulnerable to the consequences of menstruation, Chhaupadhi and other discriminatory practices. Adolescent girls have to devote time substantially to household work and farming activities. At the same time their economic contribution is not valued and not counted while there is an accent on their reproductive role. Social norms, social pressure and unequal power relationship keep adolescent girls with limited self-efficacy which impedes them from supposing that they can effectively take actions against Chhaupadhi and 


\section{4| Giri Prasad Panthi}

other unhealthy practices. While analyzing citizens empowerment on ASRH for tackling adolescent sexual and reproductive health service delivery and social behavior change; still a sizeable citizen exhibited less confident to use their individual agency to decide freely, speaking up against existing traditional norms (Panthi, 2016).

In this backdrop, the researcher attempted to analyze some sexual and reproductive health related practices form the lens of social norms theory and looked in to what is the perception of citizens on selected practices to gauze social influence and their readiness to change.

\section{Social Norms and Social Behaviors}

Social norms include a broad range of attitudes, beliefs, behaviors, cultural traditions, community standards, customs, shared beliefs and common behavioral patterns. Social norms are powerful because they influence behavior or practice of people in either unhealthy or healthy ways depending on believe of individuals. Hence, social behaviors are underpinned by social norms Bicchieri (2008). In this context we have to understand how social practices or social behaviours are determined by social norms. According to Bicchieri (2006) human behaviors are influenced by interaction of social expectations, attitudes or normative beliefs and factual beliefs. Social norms are pattern behavior because people believe that most people in their reference network conform either as empirical expectations or normative expectations. Literature on social norms point out that people comply with norms because they internalize the values alive in those norms. They are rewarded by compliance and wants to avoid sanctions by community if they noncompliance. In other way we can say that they gain from compliance and they lose form challenging norms (Boudet et al., 2012). 
Dhaulagiri Journal of Sociology and Anthropology Vol.11, 2017|155

According to Bicchieri (2013) the practice of analysis of social norms or use of social norms theory in social behaviour change was initially adopted in the field of health promotion such as promotion of breastfeeding, sanitation promotion and smoking cessation. Most of them are roots from social conventional theory. Analysis of social norms provides very important insights in to minutely look in what norms are and how they influence behavior. The social influence by norms is generally based on social learning theory (Bandura, 1977) particularly theory of planned behavior and reasoned action theory (Ajzen, 1991).

Furthermore, elaborating social norms theory, Bicchieri (2008) argues that social norms theory holds subjective norms or the perceived expectations of other people in the community who approve or disapprove of a particular behavior in a particular community. A social norm theory hypothesizes that people are highly influenced by what their peers are doing or thinking and then conforms what they believe is the norm, or social expectation. Thus, people may overestimate the value of problem behaviors and underestimate healthy behaviors, tending to increase problem behaviors. Social norm theory also suggests that subjective norms that come from incorrect assessment of what others do will influence social behavior (Berkowitz \& Perkins, 1987).

There are many strategies being tested for ending discriminatory social norms and practices around the world but the challenge is to identify the most effective strategies in a particular context to understand which change action is most effective or least effective. Recent literature on game theory of social convention has indicated how planned attempt can be effective to shift 'sticky' norms such as preference of marriage at early age (Bicchieri, 2007). Moreover, Mackie and Jeune (2009) argue that social behavior change requires a critical mass who act as social role modeling. 


\section{6| Giri Prasad Panthi}

Such social role modeling can be initiated by both individual and collective agency for example, a few girls' or households' decisions can challenge discriminatory and unhealthy social norms which may start to shift social norms in the wider community. Similarly, collective campaign of groups, community based institutions can play a critical role in transforming social norms and public policies from below.

According to Boudet et.al (2012) understanding agency is also vital for understanding opposition to gender equality and backlash against changing social gender norms. Agency and orthodoxy or changing with norms is profoundly affected by socioeconomic circumstances (Mackie \& Jeune, 2009).Creating a supportive social environment is a social obligation of community and citizens. Community engagement is critical for successful strategies to influence social norms (WHO, 2009).

\section{Method}

The study aimed to examine citizen's perspectives on adolescent sexual and reproduced health and related social norms and practices. Quantitative, cross-sectional, survey, descriptive and analytical research design was used for the study. The target populations for this study were 2126 Citizens affiliated with the five categories of Community Based Institutions (CBIs) namely Ward Citizen Forum (WCF), Citizen Awareness Center (CAC), Youth Network (YN), Adolescent Girls Circle ( GGC) and Women Group ( WG) from Dasarath Chand, Patan, Siddeshwor and Bhauneli area in Baitadi district of Nepal. Data were generated through questionnaire survey by proportional allocation of sample to five categories of community based institutions mentioned above .Out of total number of population $(\mathrm{N}=2126)$, sample size $(\mathrm{n}=337)$ was determined by 
Dhaulagiri Journal of Sociology and Anthropology Vol.11, 2017|157 using 95\% level of confidence at 0.05 acceptable margin of error.

Data were recorded in the data entry master excel sheet and tabulated as per number of responses for each questionnaire and entered in to SPSS 16.0 version for further analysis. Descriptive statistics and inferential statistics were used for data analysis. This article is prepared based on the finding to only one of the research questions out of six to know the answer of to what extent citizens affiliated with different community based institutions were ready to abandon traditional unhealthy practices and promote supportive social environment for adolescents? In order to search appropriate answers of the research questions, both descriptive statistical and factor analysis were performed.

\section{Result}

The social acceptance and resistance level of citizen related to common traditional practices related to adolescent sexual and reproductive health were assessed to reveal to understand to what extent citizen's perception was influenced by social norms. To assess citizen perceptions different 8 statements were administered by using Likert Scale of rating scores ranging from 1 to 5 . Here, 1 stands for strongly disagree about the statement, 2 for disagree, 3 for neither agree nor disagree, and 4 for agree, and finally 5 for strongly agree. These eight statements belong to prevailing social norms on Adolescent Sexual and Reproductive Health. The researcher has performed both descriptive statistical and factor analysis with the following results. 
Table 1: Descriptive Analysis of Citizens Acceptance on Social Practices

\begin{tabular}{lccc}
\hline Social Norms / Practice- Statements & Mean & $\begin{array}{c}\text { Std. } \\
\text { Devi- } \\
\text { ation }\end{array}$ & Analysis N \\
\hline $\begin{array}{l}\text { 1. Provide Sexuality Education to } \\
\text { adolescent in School }\end{array}$ & 3.35 & 1.826 & 337 \\
$\begin{array}{l}\text { 2. Talking about sex between ado- } \\
\text { lescents and their parents }\end{array}$ & 2.65 & 1.574 & 337 \\
$\begin{array}{l}\text { 3. Allow to stay at home during } \\
\text { mensuration and give food as usual }\end{array}$ & 2.50 & 1.442 & 337 \\
$\begin{array}{l}\text { 4. Allow to Go to School During } \\
\text { Mensuration }\end{array}$ & 2.47 & 1.624 & 337 \\
$\begin{array}{l}\text { 5. Voluntary choice of life partner } \\
\text { by boys and girls }\end{array}$ & 2.60 & 1.403 & 337 \\
$\begin{array}{l}\text { 6. Allow to stay inside home } \\
\text { during delivery }\end{array}$ & & & \\
$\begin{array}{l}\text { 7. Use of family planning service } \\
\text { by unmarried adolescents }\end{array}$ & 2.60 & 1.481 & 337 \\
$\begin{array}{l}\text { 8. Voluntary abortion services by } \\
\text { adolescent and young girls }\end{array}$ & 2.59 & 1.441 & 337 \\
\hline & & & \\
\hline
\end{tabular}

Five point (1-5) Likert Scale is used for rating the agreement about the statements. Average score for this scale is 3 with standard deviation of 1.58 for 5 scores. On the average, ' 3 ' stands for response/rating belonging to "Neither agree nor disagree" for a given statement. Below this average indicates disagreement with the statements. Likewise, above this average indicates agreement about it.

According to this rating scale, the average scores for all statements from $2-8$ have below 3 score with standard deviations (1.441-1.624). In such scenario of citizens' perception reveals that 
Dhaulagiri Journal of Sociology and Anthropology Vol.11, 2017|159 citizens they are sticky to current social norms and practices and do not agree to abandon such practices. Regarding sending girls during mensuration, with the average rating scale (with S.D 1.624), the citizen's showed strong disagreement. Similarly, with standard deviation (1.574) discussion between parents and their adolescent sibling about sex for this statement refers some variability in the perception for this norm. Adding one Standard Deviation to the average seems some degree of agreement about this statement. Subtracting on three Standard Deviation to the average shows severe disagreement about it. There is more weight of the rating scale towards the disagreement.

Likewise, citizen showed disagreement "to allow to stay inside the same house and to give food as usual during menstruation". Similarly, the study revealed that that citizens have strong disagreement to allow girls and boys "to make independent decision to choose life partner for marriage, to allow women to touch without restrictions after delivery, allow unmarried person to use of contraceptive and to allow adolescent and young women to take abortion services". Nevertheless, citizens seemed a bit liberal on the statement that "adolescents can be provided sexuality education in school since the average rating score is 3.35 (with SD 1.826) just above 3. In an average they agree that sexuality education can be provided in schools. Hence, these eight statements are positive social norms and behaviors that require to adopt to promote education, health and development of adolescent.

Furthermore, result produced by factor analysis with Varimax method on each of these eight statements in the form of agreement or disagreement is presented in the following Table 2:- 
Table 2: Citizens' Perception on Social Behavior related Statements

\section{Component Matrix}

1.Provide sexuality education to adolescent in school

2. Talking about sex between adolescents and their parents

3.Allow to stay at home during menstruation and give food as usual

4. Allow to go to school during mensuration

5. Voluntary choice of life partner by boys and girls

6. Allowing to stay inside home during delivery period

Component

1

$-.556$

.778

.802

7. Use of family planning service by unmarried adolescents

8. Voluntary abortion services by adolescent and young girls

Principal Component Analysis, a. 1 Components extracted, Extraction Method: Varimax. Single component

The second column of above table is \pm loadings of eight statements showing their contribution with the component/factor that citizens agree/disagree with their expectation associated with sexual and reproductive health related practices against social norms. Positive values indicate the positive relation with the factor and negative values for negative relation with it. In other words, the positive value stands for disagreement whereas negative value stands for agreement. This criterion is guided by Table 1.

According to Table 2, ' statement 3' has most contribution to the factor and is followed by '4', 6', '2', '5', 7' and ' 8 ' and ' 1 '. 
Dhaulagiri Journal of Sociology and Anthropology Vol.11, 2017|161

Hence, more the loading is, more the severe restriction imposed by prevailing social norms and. less the loadings is, less the restriction of the norms. According to this, citizens are showing most interest not to allow the adolescents girls and women to stay inside the same house and provide foods without discrimination during menstruation period. This chronic restriction is faced by adolescent's girls and women in the community. The second most restricted criterion is not allowing the girls to go school during menstruation. Others are so forth.

\section{Discussion}

Despite proliferation of community based institutions and ongoing awareness and empowerment activities at the community level, still majority of citizen have flaunted reluctance to abandon traditional unhealthy practices. The study revealed that citizens are adhered to traditional practices and are not ready to abandon traditional discriminatory and unhealthy practices replacing by adopting the positive social practices presented in the eight statements. According to the average rating scale, the social norms seem very strong to continue menstrual restrictions related practices such as allow menstruating girls to go to school, this is strong sign of citizen's tendency to adherence on tradition. However, the study shows that citizens are slightly liberal on providing sexuality education to adolescents in school. Similarly, there is strong barrier in intergenerational discussion or talking about sexual \& reproductive health related matters between parents and adolescent. This study evidences that that there is strong force of the social norms which impeding to achieve better adolescent sexual and reproductive outcomes. 


\section{Conclusion}

The prevailing discriminatory social practice of isolation, restriction and negligence of education and health during mensuration are violation of rights of adolescents. The status of attitudes and prejudices of citizens who are in the leadership position is strongly detrimental to avert such practices. The findings of the study reflects their poor understanding and information about needs and rights of adolescents. Majority of the citizens demonstrated reservations for promoting positive practices because of cultural, religious and perceived eligibility reasons based on social norms. There is conflict and contradiction between citizen's social and traditional values, existing laws, policies and adolescent's rights to education and ASRH services. The citizen, therefore are wavering between their personal feelings due to fear of direct or indirect social sanction. Therefore, for ending unhealthy and discriminatory traditional practices, it requires social norms changing initiatives in massive scale, rigorous sensitization to produce critical mass, social role modeling to bring courage for change and step up for positive social deviant by citizens affiliated with community based institutions.

\section{References}

Ajzen, I. (1991). The Theory of Planned Behavior. Organizational Behavior and Human Decision Processes, 50, 179-211.

Bandura, A. (1977). Social Learning Theory. Englewood Cliffs, NJ: Prentice-Hall. Barton,

Berkowitz, A. D. \& Perkins, H.W. (1987). Current Issues in Effective Alcohol Education Programming. In Joan Sherwood (Ed): Alcohol Policies and Practices on College and University Campuses, p 69-85, Columbus.

Bicchieri, C. (2006). Habits of the mind" in The Grammar of Society: The Nature and Dynamics of Social Norms. Cambridge University Press. 
Dhaulagiri Journal of Sociology and Anthropology Vol.11, 2017|163

Bicchieri, C. (2007). Game Theory: Some Personal Reflections",

V. F. Hendricks and P. G. Hansen, eds., Game Theory 5

Questions. Automatic Press.

Bicchieri, C. (2008). "Social Norms", Lecture at the UNICEF Global Consultation On Social Norms, New York.

Bicchieri, C. (2013). Norm Manipulation, Norm Evasion: Experimental Evidence, Economics and Philosophy 29, 2013: 175-198

Boudet, A.M., Petesch, P. \& Turk, C., (2012). On Norms and Agency. Conversations about Gender Equality with Women and Men in 20 Countries. Washington, DC: World Bank.

Crawford M, Menger LM, and Kaufman MR (2014). 'This is a Natural Process': Managing Menstrual Stigma in Nepal. Cult Health Sex. 16(4): p426-39.

Kadariya, S., \& Aro, A. R. (2015). Chhaupadi Practice in Nepalanalysis of ethical aspects. Medicolegal and Bioethics (Date Accessed: 7 July, 2016).

Mackie, G. \& Jeune, J. (2009). Social Dynamics of Abandonment of Harmful Practices: A New Look at the Theory. Special Series on Social Norms and Harmful Practices Working Paper 2009-06. Florence, UNICEF Innocenti Research Centre.

Panthi, G. P. (2016). Social Accountability for Adolescent Sexual and Reproductive Health. Himalayan Journal of Sociology and Anthropology, 7, 13-39. doi:http://dx.doi.org/10.3126/ hjsa.v7i0.17149

UNICEF \& CBS, (2010). Nepal Multiple Indicators Cluster survey, mid and Far Western Regions, Nepal

WHO (2009). Changing Cultural and Social Norms that Support Violence. Geneva:

Panthi, Giri Prasad (ORCID: 0000-0002-9827-5699) is currently a $\mathrm{Ph} . \mathrm{D}$ Scholar in Sociology, Singhania University Rajasthan, India. He is a development professional with 17 Years' experience in program management, health system strengthening and capacity building in the filed of Reproductive Health,Population dynamics and Gender .His research interest areas are adolescent sexual and reproductive health, community governance and social accountabiliity.

Email: giripanthi@gmail.com 